\title{
La hora de clase: por una erótica de la enseñanza
}

Recalcati, M (2016) La hora de clase: por una erótica de la enseñanza. Barcelona: Anagrama.

Comentario a cargo de: Gladys Rodríguez Jourdan.

Docente de Pedagogía. Lic. en Ciencias de la Educación, Universidad de la República. Diplomada en Educación y Desarrollo Administración Nacional de Educación Pública, Universidad de la República.

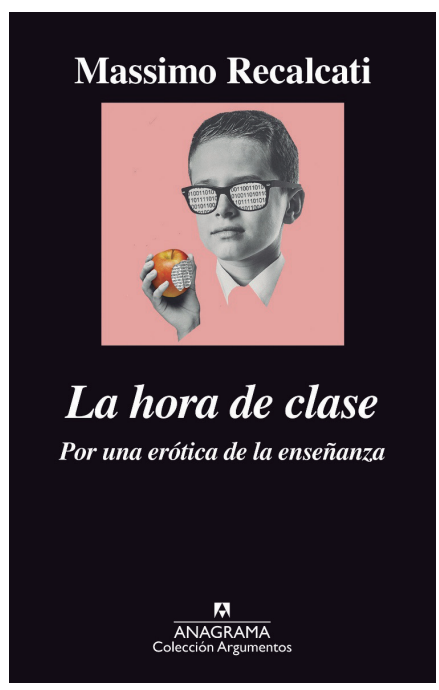

Si bien, se trata de un libro escrito en el año 2016, podría decirse que la pandemia del Covid-19, reafirma el planteo de Mássimo Recalcati, en cuanto a resaltar la significación de las instituciones, de los enseñantes y de las relaciones educativas. Docentes desacreditados, sintiéndose muchas veces en los márgenes de la sociedad, humillados económica y socialmente, experimentaron y sintieron el abrazo de estudiantes y familias. Recalcati, nos ofrece elementos para dar respuesta a algunos de esos desafíos.

La tesis principal del libro es que, lo que permanece en las instituciones educativas, en su papel insustituible, es el enseñante. El enseñante es el encargado de abrir el sujeto a la cultura como lugar de "humanización de la vida" e ir al encuentro de la dimensión erótica del conocimiento. Racalcati recurre, durante el desarrollo de su pensamiento, a una estética del lenguaje que nos invita a leerlo con placer, a reaccionar y a sorprendernos, a parar la lectura y ponernos a pensar en nuestras experiencias cotidianas.

A lo largo de su desarrollo, lo pedagógico se nutre de aspectos de la psicología y la filosofía para fundamentar diferentes conceptos que recorren la obra, sobre todo el concepto de erótica de la enseñanza que da título al libro.

Este profesor italiano se posiciona como un enemigo del reciclaje del conocimiento, de lo ya hecho y dicho, porque permanece igual a sí mismo, generando aburrimiento, conformismo, sensación de asfixia, anorexia intelectual. De esa forma desaparece el amor por el conocimiento y se reduce a una cuestión meramente administrativa, inhabilitando la sorpresa. Los libros se vuelven mercancías, se pretende hacer carreras rápidas y económicamente redituables. Y así, se reduce casi todo, al cultivo de mundos tecnológicos y virtuales, haciendo que las "cabezas funcionen como ordenadores, como mapas cognitivos que requieren sus actualizaciones". Esa es la escuela perdida. En cambio, los libros pueden colaborar en disipar la cultura de la muerte, es decir, significan una coartada al camino de los jóvenes hacia la drogadicción, bulimia, anorexia, depresión, violencia, alcoholismo. Las escuelas llenas de libros, son capaces de poner a los jóvenes frente a mundos nuevos, muchas veces diferentes a los mundos familiares, amparando lo humano, el encuentro con el otro, el eros del conocimiento.

\section{De la escuela perdida al trauma positivo de la escuela}

En el hiperhedonismo del capitalismo individualista, se deja a la educación en el lugar de una baratija para producir habilidades eficientes y adecuadas a sus necesidades bajo el principio del rendimiento cognitivo, la eficiencia, la competencia y el hacer. En lugar de promover que los estudiantes se planteen problemas, esta racionalidad se preocupa por hacer que resuelvan problemas que alguien, alejado de las aulas, los pensó como tales y les manda resolver. Se parece más bien a un totalitarismo blando, narcotizante y excitante de objetos de goce que han invadido la vida de nuestros jóvenes, eclipsando el pensamiento crítico. Lo necró- 
filo de la escuela es la repetición de lo mismo, sin invención ni deseo, que lo único que hace es consolidar la ignorancia a través de la propia institución.

El erotismo en la enseñanza que promueve el autor, implica pensar en el encuentro del educador o educadora con la palabra, no sólo que sabe el saber, sino que sabe testimoniar que el saber puede ser amado, que sabe abrir mundos a través del poder erótico de la palabra y del saber que la palabra hace vibrar. Recorrer el vacío en el saber del otro, haciendo del saber un objeto que provoca el deseo de los educandos. El mayor regalo del maestro es dejar al estudiante "siempre libre de irse, de separarse del maestro".

Se trata de un movimiento de alejamiento de lo traumático que puede significar la obligatoriedad de la escuela como algo obvio al que se tiene que asistir, transformando la obligatoriedad en un acto educativo que sea incitación a la vida, es decir, una superación de lo esperado a una apertura ilimitada. A partir de las raíces, de la pertenencia al hogar, a la familia, que marca identidad y protección, el acto de educar tiene que ser un impulso hacia la posibilidad original de adquirir experiencias de apertura, al mismo tiempo que el estudiante va aprendiendo a descentrarse del yo. La función de la escuela sigue siendo la de abrir mundos.

En este sentido educere se familiariza con seducere como forma de apertura, claridad, conducir lejos, conducir al aire libre, a un claro. Sin deseo de saber no hay posibilidad de subjetivación del aprendizaje, sin erotizar la palabra no es posible conectar el saber a la vida que es lo que permite abrir puertas y ventanas a otros mundos. Se hace necesario el encuentro con el otro, en donde el yo es el otro y así poder concebir el encuentro educativo como hospitalidad.

Si la escuela queda en el lugar mortífero de repetición de lo mismo, si se transforma en un lugar que patrocina la eficiencia, la adquisición de competencias como índice de productividad, o en un lugar que se transforma en un parque infantil, para entretener y distraer, si queda reducida a un lugar de "examendería", entonces la escuela será el lugar donde se consolida la ignorancia institucionalizada.

Tras el concepto del "trauma positivo de la escuela", el autor resalta el valor beneficioso de la obligatoriedad de asistir a la escuela. No obstante, destaca que el trabajo de los profesores se ha convertido en una labor de frontera, esto es, sustituir a familias angustiadas o inexistentes, oponerse al mundo muerto del consumismo, al poder de seducción de las nuevas tecnologías. La obligatoriedad de asistir a la escuela y la presencia de docentes pueden permitir reactivar los lugares vitales de la escucha y de la palabra, del encuentro, de la acción colectiva, del erotismo de la palabra, pueden permitir reavivar deseos, proyectos y creaciones colectivos.

\section{La belleza de la hora de clase}

Cuando aparecen los agoreros de la evaporación de la escuela, él reafirma que el verdadero lugar de la escuela está en la belleza de las horas de clase, como lugar de aventuras, de encuentros emocionales e intelectuales. Recalcati piensa que un buen enseñante es aquel que cree, que una hora de clase, puede cambiar la vida de los estudiantes.

Volviendo a la pandemia, donde parece colarse la idea de la autoformación, Recalcati descarta de plano esa idea. La autoformación es pura ilusión porque la educación requiere de un otro: un docente, un enseñante, que sustenta su enseñanza en el amor por el saber que es amor por una carencia que nos atrae y hace causar el deseo de conocer en el otro.

Muchas veces, la hora de clase se ve afectada por la burocratización de la tarea del docente, responder preguntas de las autoridades, informatización de las herramientas didácticas, encarnizamiento evaluativo, la imposición de una razón tecnológica cognitiva.

Sin embargo, un profesor o profesora puede cambiar la vida de cualquier estudiante. Puede hacer que un libro haga que un cuerpo no se canse de leer y de devorar, cuerpo hecho de páginas y escrituras. La función de la hora de clase, consistiría en "generar cuerpos eróticos de los objetos del saber". La posibilidad de que el cuerpo se vuelva libro, significa el nombre más alto del encuentro amoroso con el saber. El educador es el único capaz de amplificar el horizonte del mundo, porque es el único capaz de envolver el saber elevándolo a un objeto capaz de causar el deseo en los estudiantes. La belleza de la hora de clase se da en un espacio institucional, espacio para la sorpresa y la emoción. "Sólo la experiencia de lo cerrado empuja hacia la necesidad de la apertura".

Las relaciones entre profesores y estudiantes son simbólicamente asimétricas. Pero la belleza de la hora de clase radica en el deseo de enseñar que no es un deseo de guiar las vidas o las conciencias, sino el de enseñar, unido al conocimiento de lo que enseña sin que haya un propósito deliberado de formar, aunque resulte un proceso de formación. La belleza de la hora de clase ra- 
dica en que llegue ese docente que no se olvidará, ese que dejará huellas indelebles en nuestras vidas. Y, qué interesante que Recalcati, un profesor italiano, mencione a la profesora Idea Vilariño para referirse a las profesoras memorables, memorables porque lo que queda no es (...) "el contenido del conocimiento, sino la transmisión del amor por el conocimiento".

En otra parte del libro, aludiendo a Lacan. se refiere al estilo de los profesores. La belleza de la hora de clase necesita de un profesor portador de un estilo, una manera de dar forma a una fuerza, una voz que encarna una auténtica corporeidad, la manera que trasluce su forma de entrar, él o ella, al conocimiento, de avivar el saber, de engancharlo a la vida, de darle vida a conocimientos que puedan parecer muertos, "de habitar una ética de testimonio que rechaza cualquier criterio normativo de ejemplaridad".

El planteo del autor está lleno de metáforas como forma de buscar la coherencia entre lo que escribe y la erótica que tiene que envolver la enseñanza para que el docente encuentre la belleza en cada hora de clase. El tropiezo del maestro y la belleza de la torcedura son casi las dos metáforas finales del libro. El enseñar y el aprender son un misterio para Recalcati porque no se sabe cómo sucede, no hay una relación directa entre lo que hace el docente y el estudiante en ese movimiento subjetivo. Pero sí está seguro que el estudio, por más auténtico y apasionado que se realice no escapa a los tropiezos, a las torceduras, como imprevistos de la vida que hacen posible la búsqueda de la verdad. 